sensitive organisms are the same as those found in a similar larger series in our area three years ago.

The coliforms and Proteus spp. isolated from patients with conditions such as bladder dysfunction, obstructive lesions of the urinary tract, or who have been catheterized, are much more frequently resistant. For example, in a genitourinary surgical unit only $12 \%$ of the coliforms isolated were sensitive to sulphonamides. We feel that the difference between organisms causing infections of this type (where a large proportion are not Esch. coli) and those causing acute infections outside hospital needs emphasizing. The essential points in the technique of testing for sulphonamide sensitivity have been clearly restated by Dr. P. C. C. Brown and his colleagues (19 October, p. 190). Sulphonamide sensitivities cannot be performed satisfactorily unless the medium is free of sulphonamide inhibitors and attention is paid to the size of the inoculum. On these grounds it is difficult to assess the significance of the results obtained by Dr. M. H. Robertson (12 October, p. 121). ${ }^{1}$

From our experience of patients seen in north and south Manchester there is no evidence of the development of drug resistance to a degree that should discourage general practitioners in this area from the initial use of sulphonamides for treating acute urinary tract infections.-We are, etc.,

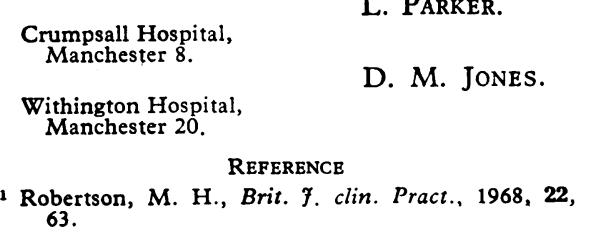

\section{Deep Vein Thrombosis}

SIR,-We would like to make the following comments in reply to the criticisms of $\mathrm{Mr}$. A. Singer (9 November, p. 386) of our recent papers (21 September, p. 717, and 9 December 1967, p. 596).

We do not underestimate the risk of pulmonary embolus, consequently almost all our clinical research has been directed towards preventing second and recurrent emboli.

The paper on streptokinase was a preliminary communication pointing out that it does dissolve fresh thrombus. It does not give our views of its place in the overall treatment of deep vein thrombosis and pulmonary embolism. Indeed, it states "we did not feel justified in using it in those with large iliofemoral thrombi because of the hazard of embolism during treatment."

We believe that phlebography can clearly define the nature and extent of deep vein thrombosis and that subsequent treatment should be based on the phlebogram. Plicating the vena cava is often unnecessary and is as illogical a form of treatment as relying solely on anticoagulants. The results of the approach that we suggested in our preliminary communication (9 December 1967, p. 596) will be published within the next six months, but we can state at this time that they are far superior to any other regimen we have followed, and equal to the $97-98 \%$ guarantee that Mr. Singer claims for caval plication.-I am, etc.,

\section{Department of Surgery. \\ St. Thomas's Hospital \\ London S.E.1.}

\section{Through-knee Amputations}

SIR,-May I write in strong support of the through-knee amputation in the elderly patient as advocated by Mr. P. F. Early in his recent article (16 November, p. 418). On the vascular surgical service at the Central Middlesex Hospital this has now become the procedure of choice for the severely ischaemic limb in which restoration of arterial flow is not possible.

I should particularly like to emphasize the enormous advantage that this operation has in permitting early rehabilitation in the older age groups. Two factors are responsible for this. First, the patients can be measured for a pylon before amputation is carried out. And, secondly, muscular control and proprioception in the stump are so well retained that patients learn to walk on the pylon very rapidly.

Working in close collaboration with the Limb Fitting Centre at Roehampton, we have now reduced the total inpatient stay after amputation in uncomplicated cases to between 21 and 28 days. Before discharge the patients must be able to walk independently, usually with only one stick, and negotiate stairs without help. The effect of a rapid rehabilitation policy on the morale of both patients and nursing staff has been quite dramatic. To the patient, the knowledge that even before he loses his leg a prosthesis is being made for him on which he is expected to walk is a source of the greatest encouragement. Moreover, the sense of urgency to have the stump ready for the prosthesis greatly assists the work of the physiotherapist in the immediate postoperative period. Such a programme contrasts sharply with the average delay of 12 weeks between amputation and measurement quoted by $\mathbf{M r}$. Eanly, even where primary healing had been achieved, and 21 weeks when healing was retarded. Figures of this kind are unfortunately all too common, and there is no doubt that a strong case exists for all amputations to be performed in a limited number of centres, each linked to a limb-fitting centre.

One further point. Although it is true that delayed healing due to necrosis in the anterior flap is a hazard of the through-knee amputation, the incidence of this complication diminishes with experience of the technique. Even when it occurs it is not a contraindication to the wearing of a prosthesis. The area of skin loss is never on the weight-bearing surface and healing will take place satisfactorily with the pylon in full use. Indeed in several of our cases the rate of healing appears to have been accelerated when walking was encouraged.- I am, etc.,

\section{Central Middlesex JoHN Newcombe. Hospital,
London N.W.10.}

SIR, - I have read with considerable interest Mr. P. F. Early's excellent article on the results of through-knee amputations (16 November, p. 418). I was disappointed, however, to find no mention of the oldfashioned Stokes-Gritti amputation.

All the amputations I perform are for vascular disease, and where the ischaemia extends only a little above the foot disarticu- lation of the knee is doubtless the procedure of choice. Where, however, the ischaemia is approaching the knee, the long anterior flap required in this amputation all too often results in failure. In these cases I have for many years been using the Stokes-Gritti amputation even in cases where many surgeons would go above the knee. Healing may sometimes be delayed, but in a condition which is almost certainly bilateral a delay of even three months is, in my opinion, a cheap price to pay for an extra six inches of leg. I sometimes wonder, in fact, whether a little too much emphasis is placed these days on the speed of rehabilitation as against ultimate function.

My results with this amputation have been most gratifying. The two to three in. (5-7.5 $\mathrm{cm}$.) which the Stokes-Gritti allows can make all the difference, and I am assured by the limb fitters that the weight-bearing stump so produced has great advantages over the aboveknee stump. May I, therefore, make this plea for the Stokes-Gritti amputation to remain in every surgeon's repertory?I am, etc.,

\section{Ashford Hospital, Middlesex. \\ Tuberculin Test in Children with Malnutrition}

ROBIN BURKITT.

SIR,-I read with great interest $\mathrm{Dr}$. Anne V. C. Lloyd's observations on the tuberculin test in children with malnutrition (31 August, p. 529). Her results have been very similar to some of ours.

About $18 \%$ of malnourished children treated at our unit show radiological signs suggestive of pulmonary tuberculosis, ${ }^{3}$ and we also observed a negative tuberculin response in the presence of active lesions. In a preliminary study ${ }^{1}$ the intradermal tuberculin testing was performed with one tuberculin unit of purified protein derivative (this being the only standard tuberculin available) and read at 72 hours at the B.C.G. clinic of the school in 12 children (kwashiorkor/marasmus 7 and pre-kwashiorkor 5) and three adults (nutritional oedema) having suggestive radiological signs (tubercle bacilli in sputum or gastric washings could not be found), and in 20 children (kwashiorkor/marasmus 15, prekwashiorkor 5) and two adults with normal chest radiographs. Only two (one each of kwashiorkor and pre-kwashiorkor) of the $x$ ray positive children were tuberculin positive. Negative chest $x$-ray was associated with negative tuberculin response in all children except one. The adult patients irrespective of their lung signs showed positive reactions. Four radiologically positive children were kept under observation in the hospital for about six weeks. In them, the fever responded to specific treatment, serial chest radiographs showed regression of the lesions, and one of them turned tuberculin-positive. Subsequently we have confirmed these observations in a larger series of cases.

The observations of Dr. Lloyd, like our own, show that false negative tuberculin reactions can occur in kwashiorkor and marasmus. Dr. Lloyd has further shown that the difficulty in diagnosis can be overcome to a considerable extent using stronger doses of tuberculin. However, other aspects of the 
problem deserve consideration. Although high protein feeding for some weeks may at times lead to tuberculin positivity, a negative reaction does not correlate well with the degree of hypoproteinaemia. Adults with equally severe hypoproteinaemia are usually tuberculin positive, while marasmic children with better serum protein status are not. False negative reaction observed in prekwashiorkor (the condition in children characterized by retarded growth and anaemia and sometimes avitaminosis, but not showing any oedema, hypoproteinaemia ${ }^{3}$ and other biochemical changes" may be found) is significant in the prevention of tuberculosis. The routine procedure of tuberculin testing practised in many B.C.G. clinics mostly on such children appears to be of limited value. Protein-calorie deficiency may also influence the results of tuberculin surveys. Further, the tuberculin conversion rate after B.C.G. vaccination is poor ${ }^{5}$ in mild protein-calorie Jeficiency, and it is not known whether this would also affect the immunity offered by the vaccination.-I am, etc.,

\section{A. K. Bhattacharyya.}

Nutritional and Metabolic

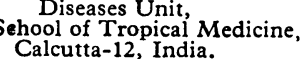

REFERENCES

1 Bhattacharyya, A. K., Mandal, J. N., and Basu, 15. P., Bull. Calcutta, Sch. trop. Med., 1967, Bhattacharyya, A. K., and Mandal, J. N., Bull.
Calcutta Sch. irop. Med., $1966,14,58$ Calcutta Sch. trop. Med., 1966, 14, 58.
Chatteriee, S., D.Phil. Thesis, 1967, Calcutta UniChatteriee,
versity.

- Dean, R. F. A., in Recent Advances in Paediatrics, ed. D. Gairdner, 1965, 3rd ed., p. 239

Harland, P. S. E. G., Lancet, 1965, 2, 719.

\section{Pneumothorax and Congenital Diaphragmatic Hernia}

SIR,-I read with interest Mr. D. G. Young's report of contralateral pneumothorax with congenital diaphragmatic hernia (16 November, p. 433). His statement that "Pneumothorax on the side of the hernia is inevitably produced at the time of operation and is treated appropriately" and the conclusions he draws are open to argument.

At the symposium on congenital diaphragmatic hernia at the meeting of the Society of Thoracic and Cardiovascular Surgeons in $1966 \mathrm{I}$ presented my experience at the Children's Hospital, Birmingham. For a number of years I have not aspirated the pneumothorax on the operated side, nor is an intercostal tube inserted. The reasoning for this is as follows. Reduction of the herni must leave a space which the extremely hypoplastic left lung cannot fill straight away, and since the number of bronchial generations is fixed from before birth, subsequent lung enlargement must involve an increase in lung size at alveolar level. The alternative mechanisms of obliterating the space would be by elevation of the diaphragm and displacement of the mediastinum to the left. In severe cases where hypoplasia of the right lung is also present mediastinal displacement is not possible.

It would seem to me that treatment of the pneumothorax on the side of the operation is neither rational nor desirable. The hypoplastic left lung is fully expanded at opera- tion and the pneumothorax is left; this then acts as a "cushion" preventing undue stress on either lung, in much the same way as the pneumothorax resulting after a pneumonectomy acts as a "cushion" for the bronchial stump. During the course of the first postoperative days the pneumothorax slowly absorbs and the lung enlarges to fill the pleural cavity.

In a series of patients requiring ventilation pre- and postoperatively, we have never seen contralateral pneumothorax and it is suggested that the cushioning effect of the pneumothorax on the operated side has prevented this complication. The high mortality of operation in those babies presenting within the first few hours of life with severe respiratory distress is usually due to the fact that they have severe bilateral pulmonary hypoplasia.-I am, etc.,

\section{Children's Hospital, KeITH D. ROBERTS. Birmingham.}

\section{Bladder Distension and Oedema of Legs}

SIR,-The interesting case reported by $\mathrm{Mr}$ Haziq-ul-Yaqin (9 November, p. 369) brings to mind a somewhat similar case seen recently.

A 59-year-old male was admitted on 9 October with swelling of both legs and abdomen Both legs had begun swelling 10 days prior to admission. The swelling increased gradually up to the day before admission, when he noticed his abdomen was swollen. Swelling of both abdo men and legs then increased rapidly. $\mathrm{He}$ had been given frusemide $40 \mathrm{mg}$. daily for five day before admission, with no apparent effect on the swelling or urinary output. There was no dysuria whatsoever.

On examination there was gross pitting oedema of both lower limbs, dilated superficial veins in both groins, a distended bladder the size of a full-term uterus, and a soft, moderately enlarged prostate. There were no clinical signs to suggest a neurogenic bladder. A diagnosis of urinary retention due to prostatic obstruction with pelvic vein compression was made. With continued catheter drainage of the bladder, the oedema subsided completely over the next fou days. The blood urea, initially $88 \mathrm{mg} . / 100 \mathrm{ml}$. also became normal during that time. There was no albuminuria and the urine was sterile. Serum proteins, electrolytes, W.R., and lumba spine $x$-ray were normal. Cystoscopy showed intravesical enlargement of both lateral lobes of the prostate. Prostatectomy was performed on 21 October. Histopathology showed benign nodular hypertrophy.

In this case the rapid increase in oedema as the bladder became more distended, the rapid disappearance of oedema when the bladder distension was relieved, and the dilated superficial veins, in the absence of any other cause for oedema of the legs, were taken as conclusive evidence of compression of the pelvic veins by the distended bladder. It was considered noteworthy that the oedema appeared before distension of the bladder was noticed by the patient.-I am, etc.,
Mercer's Hospital,
K. R. PARSAD.
Dublin 2.

\section{Treatment of Venereal Disease}

SIR,-Dr. R. R. Willcox in his letter (9 November, p. 388) accuses me of participating in a revival of controversy concern- ing the use of "epidemiological treatment" for the control of venereal diseases. I hoped I had made it quite clear in my letter (12 October, p. 122) that, far from seeking to revive this controversy, I thought the discussion quite irrelevant to your leading article (14 September, p. 630) out of which it arose, untimely, and likely to confuse. Nevertheless your correspondents seem determined to pursue this matter, so perhaps you will allow me to make a brief reply.

Dr. Willcox has referred to a discussion in 1953 , details of which were published. ${ }^{12}$ In my part of that discussion I gave in detail my reasons for believing that so-called epidemiological treatment was unsound in principle, and ineffective and often harmful in practice. I agreed that there were circumstances in which it might be expedient to use the method, but argued that such departures from the general rule should be carefully and critically examined before they were taken. Since that time I have seen no reason to change those views and nothing that your correspondents have now written inclines me to do so. Dr. Willcox seeks to make a debating point because I have advocated that the sexual partner of a patient with trichomoniasis should be treated even if it proves impossible to find the causative organism.

Trichomoniasis is a relatively trivial disease in which, however, involvement of the sexual partner is virtually certain. To treat one without the other is a waste of time. If, on examining the sexual partner and incidentally excluding more serious infection, the organism cannot be found, it seems to me wholly justifiable to make a clinical diagnosis of trichomoniasis in the partner and to treat. The situation with syphilis and gonorrhoea is quite different; they are serious diseases, mismanagement of which may do serious damage to the patient, the patient's family, and the public health. Bacteriological or, in the case of syphilis, serological confirmation of diagnosis is essential and the cases in which it is permissible to act without these are few. Indiscriminate epidemiological treatment is a serious impediment to efficient contact tracing and leads almost inevitably to a decline in clinical standards.

Dr. Willcox claims support for his views from virtually all venereologists in the United States. Perhaps it is no coincidence that, in spite of vigorous epidemiological treatment, venereal disease continues to be a bigger problem in the United States than in Great Britain.-I am, etc.,

London W.1.

$$
\text { A. J. KING. }
$$

\section{REFERENCES}

1 Willcox, R. R., Brit. ₹. vener. Dis., 1954, 30, 7.

SIR,-Your leading article "'V.D.' as a Diagnosis" (14 September, p. 630) makes the point very well that communicating a diagnosis of a venereal disease to a patient can be traumatic and must not be done promiscuously.

However, concurrent with your second precept, "Diagnosis before treatment," let us also remember another time-honoured maxim, "Never say never and never say always." An asymptomatic female reliably named as 